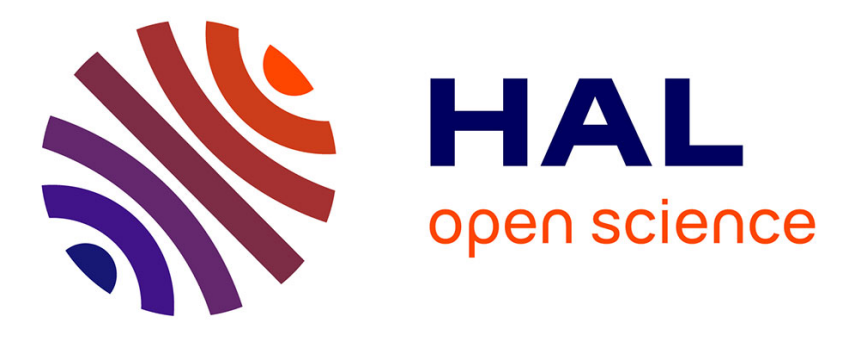

\title{
Impact of grading on steady-state strength
}

\author{
Sandra Linero Molina, Emilien Azéma, Nicolas Estrada, Stephen Fityus, J. \\ Simmons, Arcesio Lizcano
}

\section{To cite this version:}

Sandra Linero Molina, Emilien Azéma, Nicolas Estrada, Stephen Fityus, J. Simmons, et al.. Impact of grading on steady-state strength. Géotechnique Letters, 2019, 9 (3), pp.1-19. 10.1680/jgele.18.00216 . hal-02314994

\section{HAL Id: hal-02314994 \\ https://hal.science/hal-02314994}

Submitted on 14 Oct 2019

HAL is a multi-disciplinary open access archive for the deposit and dissemination of scientific research documents, whether they are published or not. The documents may come from teaching and research institutions in France or abroad, or from public or private research centers.
L'archive ouverte pluridisciplinaire HAL, est destinée au dépôt et à la diffusion de documents scientifiques de niveau recherche, publiés ou non, émanant des établissements d'enseignement et de recherche français ou étrangers, des laboratoires publics ou privés. 


\section{Accepted manuscript doi: 10.1680/jgele.18.00216}

Submitted: 03 December 2018

Published online in 'accepted manuscript' format: 10 June 2019

Manuscript title: Impact of grading on steady-state strength

Authors: S. Linero Molina* $*^{\dagger}$, E. Azema ${ }^{\ddagger}$, N. Estrada ${ }^{\S}$, S. Fityus ${ }^{\dagger}$, J. Simmons ${ }^{\|}$and A. Lizcano $^{\text {II }}$

Affiliations: *SRK Consulting Australasia, Sydney, Australia; ${ }^{\dagger}$ University of Newcastle, Newcastle Australia; ${ }^{\dagger}$ LMGC, Univ. Montpellier, CNRS, Montpellier, France ; ${ }^{\S}$ Universidad

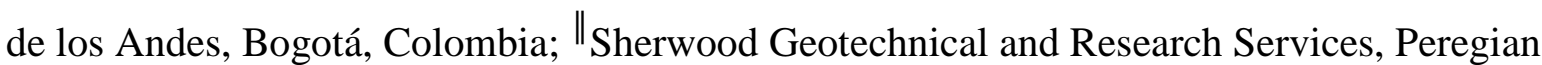
Beach, Australia and IISRK Consulting, Vancouver, Canada

Corresponding author: S. Linero Molina, Civil Engineer, University of Newcastle/SRK Consulting Australasia, Rankin Park, NSW Australia. Tel.: +61406020250.

E-mail: slinero@outlook.com, sandra.lineromolina@uon.edu.au, slinero@srk.com.au 


\title{
Accepted manuscript doi: 10.1680/jgele.18.00216
}

\begin{abstract}
In the mining industry, waste-dumps are earthen structures typically built by loose waste tipping. They may reach heights of hundreds of meters and undergo large deformations. For this reason, their stability design is based on the steady-state shear strength of the waste material. Waste materials are widely graded and may contain particles of up to metric order. Particle shape depends on the pattern of dissecting discontinuities at the source rock mass, and the relation between the size of the fragments and discontinuity spacing. The shear strength of this material is determined in the laboratory using scaled samples with altered Particle Size Distribution (PSD). However, altering the PSD is known to impact shear strength, and this impactis poorly studied. The representativeness of laboratory parameters obtained from scaled samples is thus arguable. Discrete element simulations are used here to investigate steady-state shear strength changes with alteration of the PSD when particle size and shape are correlated. It is observed, that shear strength changes result from the variation of the particle shapes induced by the alteration of the PSD. Consequently, identifying size-shape correlations and their potential impact on shear-strength is paramount when scaling materials for laboratory testing.
\end{abstract}

Keywords: Discrete-element modelling; Particle-scale behaviour; Shear strength 


\section{Accepted manuscript doi: 10.1680/jgele.18.00216}

\section{Introduction}

Open-pit mining involves partitioning waste material to areas prepared for storage. An operational challenge is designing the waste-dumps, especially in steep terrains or restricted space. Some waste-dumps in Chile are designed to contain over 1000 million tonnes of material and will reach frontal heights of up to $900 \mathrm{~m}$. (Linero et al., 2007). Improperly designed dumps may represent source of pollution or stability hazards.

Waste-dumps are typically built by loose tipping and undergo large deformations. For stability design, the steady-state shear strength of the waste material is required. However, because blasted waste contains very large particles, the material mustbe scaled in the laboratory for testing, to suit available size-constrained equipment (Lowe, 1964; Duncan et al., 2014; Fumagalli, 1969). Scaled samples have a smaller maximum particle-size and may have a different PSD shape compared with the original material.

Experimentally, it has been observed that manipulating the PSD affects shear strength, but the results are contradictory (Marachi et al., 1972; Marsal, 1972; Varadarajan et al., 2003; Linero et al., 2007; Ovalle, 2013).

Numerical research 2D and 3D suggest that steady-state shear strength is independent of PSD for materials composed of unbreakable particles with similar shape across sizes (monoshaped) (Azema et al., 2017; Azéma et al., 2017; Estrada, 2016; Voivret et al., 2009; Nguyen et al., 2015; Cantor et al., 2018). This non-intuitive result motivated the investigation of particle size-shape correlation effects in greater detail in this research.

Correlation of particle size and shape can occur due to geological settings (CIRIA et al., 2007) but it is rarely investigated. Size-shape correlation was observed for the particles between $4.75 \mathrm{~mm}$ and $75 \mathrm{~mm}$ of a mine-waste material, eroded from a sedimentary Precambrian-aged banded Iron formation in the Pilbara, Australia. This material was investigated at large-scale at the University of Newcastle. See Linero et al. (2017) for the size-shape statistics. In this correlation, larger pieces are more platy or discoidal than smaller particles. Size-shape correlation was also observed in particles between $2 \mathrm{~mm}$ and $100 \mathrm{~mm}$ quarried from a quartzitic schist in Trois Vellées, l'Orne, France. The material was investigated at large-scale at the University of Nantes in Ovalle (2013). In this correlation, smaller particles were thinner and more elongated than larger particles, in accordance with its anisotropic fabric that was prone to delamination under impacts and loads. Variability of shape by size can also be observed in Zeller \& Wullimann (1957).

When particle size and shape are correlated, scaling simultaneously alters the distributions of both particle size and particles shape. This manuscript presents the results of 18 biaxial simulations prepared to evaluate systematically the effect of material gradation and sizeshape correlation on steady-state shear strength. 


\section{Accepted manuscript doi: 10.1680/jgele.18.00216}

\section{Model description and numerical approach}

The simulations were conducted with the Contact Dynamics (CD) method (Jean \& Moreau, 1987, 1992; Jean, 1999). CD is a discrete element approach for simulation of non-smooth granular dynamics with contact laws expressing inter-particle mutual exclusion and dry friction. $C D$ is unconditionally stable and well suited for simulating rigid particles and interparticle frictional contacts; see Dubois et al. (2018), Radjaï \& Dubois (2011), and Azéma et al. (2012). The multi-purpose software LMGC90 was used for the simulations. It was developed in Montpelier and is capable of modelling collections of particles of arbitrary shape (https://git-xen.lmgc.univ-montp2.fr/lmgc90/lmgc90_user / wikis / home).

To isolate the effects of gradation and size-shape correlation of particles on steady-state shear strength, two different materials were simulated: One was composed of mono-shaped particles (same shape across all sizes), and other was composed of size-shape correlated particles, with larger particles more elongated than the smaller ones. The idealised size-shape correlation imposed was inspired by the characteristics of the material analysed in Newcastle (Linero et al., 2017).

To make the analysis systematic in terms of PSD variation, 9 different gradations were analysed, and the gradation was controlled using the size-span parameter $s$ (Voivret et al., 2007).

$$
s=\frac{d_{\max }-d_{\min }}{d_{\max }+d_{\min }}
$$

The maximum particle size $d_{\max }$ was fixed to $15 \mathrm{~mm}$, and $s$ was varied in the range $[0.1,0.2 \ldots 0.9]$ to cover a wide spectrum of gradations: from very uniform to very well-graded samples. See Figure 1.

Two simulations series were conducted. Series 1 evaluated the 9 gradations but using the material composed of mono-shaped disc particles. Series 2 evaluated the 9 gradations but using the material containing particles that are size to shape correlated.

The shape chosen to model the particles is rounded cap rectangles (RCRs) (Azéma \& Radjaï, 2010). RCRs are characterised by diameter $d$ (diameter of the inscribed circle) and aspect ratio $\lambda=L / d$ (Figure 2). A disc is a special case of RCR with $\lambda=1$, corresponding to the shape selected for the simulations in Series 1.

To achieve a systematic correlation between particle size and shape in Series 2, a continuous function was found to define the elongation of each particle as a function of its diameter and of the gradation of its sample. With this, the broad spectrum was covered from samples of uniform size and shape, to samples of very polydisperse size and shape.

Two parameters that vary in the range $[0,1]$ were introduced for convenience to define the correlation function: These are the reduced diameter $d_{r}$ and the reduced aspect ratio. $\lambda_{r} . d_{r}$ represents the relative size of a particle between $d_{\min }$ and $d_{\max }$ (Nguyen et al., 2015). $\lambda_{r}$ 


\section{Accepted manuscript doi: 10.1680/jgele.18.00216}

represents the relative aspect ratio, with $\lambda_{\min }=1$, and $\lambda_{\max }$ corresponding to the maximum aspect ratio present in a given sample.

$$
\begin{aligned}
& d_{r}=\frac{d-d_{\text {min }}}{d_{\text {max }}-d_{\text {min }}} \\
& \lambda_{r}=\frac{\lambda-\lambda_{\text {min }}}{\lambda_{\text {max }}-\lambda_{\text {min }}}
\end{aligned}
$$

To establish the correlation, and for simplicity, two hypotheses were made: (i) particle size and shape are linearly correlated (i.e., $d_{r}=\lambda_{r}$ ) and (ii) the maximum aspect ratio $\lambda_{\max }$ is also linearly correlated with $s$ in the following way:

$$
\lambda_{\max }=\lambda_{\min }+s\left(\lambda_{\max }^{*}-\lambda_{\min }\right)
$$

$\lambda_{\max }^{*}$, corresponds to the absolute maximum particle aspect ratio in Series 2 . It was arbitrarily set to 5 with the most elongated particles only present in the most widely graded sample (i.e., for $s \rightarrow 1$ ).

With the previous conditions, the aspect ratio of a particle, as a function of its size and the size-span of its sample, is given by Equation 5. In it, large particles in a sample are also more elongated, and more widely graded samples (more polydisperse in particle sizes) are also more polydisperse in particle shapes. The latter aligns with the general situation observed in the industry; mine waste is well-graded and polydisperse in shapes right after production, but sampling and scaling reduceits polydispersities.

$$
\lambda(d)=\lambda_{\text {min }}+s \frac{d-d_{\text {min }}}{d_{\text {max }}-d_{\text {min }}}\left(\lambda_{\text {max }}^{*}-\lambda_{\text {min }}\right)
$$

Particle generation to compose each sample involved the following steps:

- $\quad$ The minimum sample diameter $d_{\min }$ was determined based on desired $s$.

- $\quad$ The size range was divided into ten sub-ranges, with limits that corresponded to reduced diameters $d_{r}=0,0.1, \ldots 1$.

- $\quad$ A population of particles was generated with diameters uniformly distributed in each sub-range of size.

- $\quad$ The aspect ratio of each particle was calculated using Equation 5 and applied.

- $\quad$ Particles were sampled from each sub-range, targeting an equal total area of particles by size sub-range, and 10,000 particles in the sample.

To obtain homogeneous systems for testing, the particles of each sample were mixed and oriented randomly before placing them into a rectangular testing box. Gravity and interparticle friction were set to zero to promote homogeneous packings, and the systems were isotropically compressed at $\sigma_{0}=10 \mathrm{kN} / \mathrm{m}^{2}$ (Figure 3). The compression was maintained until 


\section{Accepted manuscript doi: 10.1680/jgele.18.00216}

coordination number (average number of contacts per particle) and packing fraction (see Equation 9) stabilised (see close-up views at the end of compression in Figure 4).

For biaxial shearing, friction between the box wall and particles was maintained to zero and inter-particle friction was set to 0.4 . The samples were biaxially sheared, by imposing a vertical velocity $v_{y}$ to the top wall of the box and maintaining the confining stress imposed for compression.

$v_{y}$ was set for an inertial number $I=5 \cdot 10^{-4}$. This condition ensured quasi-static stress state during shearing, as discussed in GRD-MiDi (2004). $I$ is defined as $\left(v_{y} / H\right)\langle d\rangle \sqrt{\rho / \sigma_{0}}$, where $H$ is the sample height, $\langle d\rangle$ is the mean particle diameter, and $\rho$ is particle density. The test was finalised at $50 \%$ of vertical strain (Figure 5).

\section{Mechanical behaviour}

The shear strength was described by the internal friction angle $\varphi$, obtained as:

$$
\varphi=\arcsin \frac{q}{p}
$$

where $p$ and $q$ are the mean and deviatoric stresses respectively. This required the stress tensor $\sigma$ to be calculated from the contact network and inter-particle force data (Rothenburg \& Selvadurai, 1981; Christoffersen et al., 1981; Bagi, 1999).

To calculate $\sigma$, the internal moment tensor $M$ of each grain ${ }^{g}$ must first be computed by:

$$
M_{i, j}^{g}=\sum_{c \in g} f_{i}^{c} \ell_{j}^{c}
$$

where $i$ and $j$ represent the components in an orthonormal reference frame, $f$ is the force exerted on the grain at contact ${ }^{c}, \ell$ is the branch vector (joining the centres of the particles in contact), and the sum runs over all contacts of the grain. The stress tensor of a granular assemblage of area $A$ is given by

$$
\sigma_{i, j}^{A}=\frac{1}{A} \sum_{g \in A} M_{i, j}^{g}
$$

The sample's density was quantified by the packing fraction $v$ :

$$
v=\frac{A_{p}}{A}
$$

where $A p$ is the area of all particles and the sample's porosity is $n=1-v$. 


\section{Accepted manuscript doi: 10.1680/jgele.18.00216}

Figure 6 presents the evolution of $q / p$ and $v$ as functions of the vertical strain $\varepsilon_{y}$.

As classically observed during a biaxial test of well-packed collections of particles, the shear stress increased rapidly at the beginning of the test, reaching a maximum value before decreasing towards a constant value at large strain (steady state). The jump observed at $\varepsilon_{y}=0$ is typical in this kind of numerical test. It reflects both rigidity of the particles and good packing at the initial state. The packing fractions reduced across the test and tended to a constant value at large strain.

Figure 7 shows the steady-state internal friction angle $\varphi_{s s}$ and packing fraction $v_{s s}$ (i.e., the average values for $\varepsilon_{y}>0.35$ ), as functions of material gradation characterised by the sizespan $s$.

In the case of discs (mono-shaped), $\varphi_{s s}$ remains almost invariant, in the range of $16 \pm 1$ degree, for any of the 9 gradations analysed (from very uniform to very well graded samples). It is established that the strength properties of granular media result from the build-up of anisotropic structures of geometrical and mechanical origins (Rothenburg \& Bathurst, 1989). The independence of strength with PSD in the case of mono-shaped particles has been discussed previously in the literature in Azema et al. (2017), Azéma et al. (2017), Estrada (2016), Voivret et al. (2009), Nguyen et al. (2015), and Cantor et al. (2018). It has been attributed to a compensation mechanism which involves both the contact orientation anisotropy which decreases with the size span, and the branch length anisotropy which behaves inversely.

In contrast, in the case of RCR particles (size and shape correlated), $\varphi_{s s}$ increases from 18 to 23 degrees when the gradation improves from $s=0.1$ to $s=0.5$; Then remains about constant between $s=0.5$ and $s=0.8$, and finally reduces for the most graded sample $s=0.9$. In this case, the mechanism explaining the behaviour is more complex as geometrical effects induced by particle size are enhanced by orientational effects introduced by elongated particles (Azéma \& Radjaï, 2010) as well as mechanical effects in presence of faceted particles (Azéma \& Radjaï, 2010; Nguyen et al., 2015). This analysis will be presented by the authors in a separate paper.

Packing fraction, as expected, increases with gradation (size-span $s$ ) for both series.

\section{Conclusions and perspectives}

Altering the PSD of materials composed of particles with the same shape across all different sizes has a marginal effect on steady-state shear strength. But in contrast, if the size and shape of the particles are correlated, the alteration of the PSD affects the steady state shear strength.

This finding suggests that shape distribution has a higher influence than size distribution on the steady-state shear strength of granular materials. 


\section{Accepted manuscript doi: 10.1680/jgele.18.00216}

This implies, that the steady-state shear strength changes observed in physical testing when the PSD is modified may be more related to the alteration in the distribution of particles' shapes than to the distribution of particles' sizes.

The results are important because correlations between the size and shape of natural and blasted materials due to geological and structural processes happens as has already been described in the literature.

Hence, sampling and scaling of coarse granular materials like mine wastes, for laboratory testing, may inadvertently cause alteration of particle shape polydispersity, making it difficult to capture the mechanical behaviour of the original material in thelaboratory.

Alteration of the particle shape polydispersity in sample preparation for physical testing should be recognised and its potential implications discussed in standard geotechnical practice.

\section{Acknowledgements}

Thanks to Fortescue Metals Group Ltd. for funding this research along with SRK Consulting, the University of Newcastle and the Australian Government Department of Education and Training. This work has been also supported by the project Ecos Nord No. C19P01/63672. Thanks to Aaron Scott and Remy Mozul for IT support at the University of Newcastle and Montpelier respectively.

\section{Notations}

$d_{\max } \quad$ maximum particle size

$s \quad$ size-span parameter

$d \quad$ diameter

$d_{r} \quad$ reduced diameter

$\lambda_{\max }^{*} \quad$ corresponds to the absolute maximum particle aspect ratio in Series 2

$p$ and $q \quad$ are the mean and deviatoric stresses respectively

$M \quad$ moment tensor

$i$ and $j \quad$ represent the components in an orthonormal reference frame 


\section{Accepted manuscript doi: 10.1680/jgele.18.00216}

\section{References}

Azéma, E., Estrada, N. \& Radjai, F. (2012). Nonlinear effects of particle shape angularity in sheared granular media. Physical Review E 86, No. 4, 041301.

Azéma, E., Linero, S., Estrada, N. \& Lizcano, A. (2017). Does modifying the particle size distribution of a granular material (ie, material scalping) alters its shear strength? European Physical Journal Conferences. 140, No. 06001, doi:DOI: 10.1051/epjconf/201714006001.

Azema, E., Linero, S., Estrada, N. \& Lizcano, A. (2017). Shear strength and microstructure of polydisperse packings: The effect of size span and shape of particle size distribution. Physical Review E 96, No. 022902, doi:10.1103/PhysRevE.96.022902.

Azéma, E. \& Radjaï, F. (2010). Stress-strain behavior and geometrical properties of packings of elongated particles. Physical Review E 81, No. 5, 051304.

Bagi, K. (1999). Microstructural stress tensor of granular assemblies with volume forces. Journal of Applied Mechanics 66, No. 4, 934-936.

Cantor, D., Azema, E., Sornay, P. \& Radjai, F. (2018). Rheology and structure of polydisperse three-dimensional packings of spheres. Physical Review E 98, 052910.

Christoffersen, J., Mehrabadi, M. \& Nemat-Nasser, S. (1981). A micromechanical description of granular material behavior. Journal of Applied Mechanics 48, No. 2, 339-344.

CIRIA, CUR \& CETMEF (2007). The rock manual - the use of rock in hydraulic engineering. 2 edn., London: C683, CIRIA.

Dubois, F., Acary, V. \& Jean, M. (2018). The contact dynamics method: A nonsmooth story. Comptes Rendus Mécanique 346, No. 3, 247-262.

Duncan, J. M., Wright, S. \& Brandon, T. L. (2014). Soil strength and slope stability. 2 edn., Wiley.

Estrada, N. (2016). Effects of the grain size distribution on the packing fraction and shear strength of frictionless disk packings. Physical Review E .

Fumagalli, E. (1969). Tests on cohesionless materials for rockfill dams. Soil Mechanics and Foundation Division ASCE 6353, No. SM1.

GRD-MiDi, G. (2004). On dense granular flows. The European Physical Journal E 14, No. 4, 341-365.

Jean, M. (1999). The non-smooth contact dynamics method. Computer Methods in Applied Mechanics and Engineering 177, No. 3-4, 235-257.

Jean, M. \& Moreau, J. J. (1987). Dynamics in the presence of unilateral contacts and dry friction: a numerical approach. In Unilateral Problems in Structural Analysis-2, Springer, pp. 151-196.

Jean, M. \& Moreau, J. J. (1992). Unilaterality and dry friction in the dynamics of rigid body collections. In Proceedings of Contact Mechanics International Symposium, vol. 1, pp. 31-48.

Linero, S., Fityus, S., Simmons, J. \& Cassidy, J. (2017). Trends in the evolution of particle morphology with size in colluvial deposits overlying channel iron deposits. European Physical Journal Conferences. 140, No. 14005, doi:DOI: 10.1051/epjconf/201714014005.

Linero, S., Palma, C. \& Apablaza, R. (2007). Geotechnical characterization of waste material in very high dumps with large scale triaxial testing. In Slope Stability 2007 (ACG, ed.), Australian Centre for Geomechanics. 


\section{Accepted manuscript doi: 10.1680/jgele.18.00216}

Lowe, J. (1964). Shear strength of coarse embankment dam materials. In Congress on Large Dams ICOLD, vol. 3, pp. 745-761.

Marachi, N. D., Chan, C. K. \& Seed, B. (1972). Evaluation of properties of rockfill materials. Journal of Soil Mechanics and Foundation Division (JSMFD), American Society of Civil Engineers (ASCE) 98, No. SM1, 95-115.

Marsal, R. J. (1972). Resistencia y compresibilidad de enrocamientos y gravas, vol. 306. México: UNAM, Instituto de Ingeniería.

Nguyen, D.-H., Azema, E., Sornay, P. \& Radjai, F. (2015). Effects of shape and size polydispersity on strength properties of granular materials. Physical Review E 91, No. 032203.

Ovalle, C. (2013). Contribution a l'etude de la rupture des grains dans les materiaux granulaires. Theses, Ecole Centrale de Nantes (ECN), URL https://tel.archivesouvertes.fr/tel-00979827.

Radjaï, F. \& Dubois, F. (2011). Discrete-element modeling of granular materials. isbn: 9781-84821-260-2. Wiley-Iste.

Rothenburg, L. \& Bathurst, R. (1989). Analytical study of induced anisotropy in idealized granular materials. Geotechnique 39, No. 4, 601-614.

Rothenburg, L. \& Selvadurai, A. (1981). A micromechanical definition of the cauchy stress tensor for particulate media. Mechanics of Structured Media , 469-486.

Varadarajan, A., Sharma, K. G. \& Venkatachalam, K. (2003). Testing and modeling two rockfill materials. Journal of Geotechnical and Geoenvironmental Engineering ASCE 129, No. 3, 206-218.

Voivret, C., Radjai, F., Delenne, J.-Y. \& El Youssoufi, M. S. (2007). Space-filling properties of polydisperse granular media. Phisical Review E. 76, No. 021301, 12.

Voivret, C., Radjai, F., Delenne, J.-Y. \& El Youssoufi, M. S. (2009). Multiscale force networks in highly polydisperse granular media. Physical Review Letters 102, No. 17, 178001 .

Zeller, J. \& Wullimann, R. (1957). The shear strength of the shell materials for the goeschenenalp dam, switzerland. In Proceedings of the Fourth International Conference on Soil Mechanics and Foundation Engineering, vol. 2, London: ISSMGE, pp. 399-404. 


\section{Accepted manuscript doi: 10.1680/jgele.18.00216}

\section{Figure captions}

Figure 1. Particle size distribution of tested samples, with uniform solids volume by particle size. The colours illustrate the different values of size-span used $s$. The limits $s \rightarrow 0$ and $s \rightarrow 1$ represent uniform and very well graded samples, respectively.

Figure 2. The particles were rounded cap rectangles (RCR). (a) RCR with aspect ratio $\boldsymbol{\lambda}=\boldsymbol{L} / \boldsymbol{d}>1$, (b) Disc (i.e., RCR with $\boldsymbol{\lambda}=1$ ).

Figure 3. Frontal view. Sample of RCR particles and size-span $s=0.3$ (a) Close-up view of the particles at Initial state, after deposition (b) Close-up view of the particles at the end of the isotropic compression. The colour scale represents total compression displacements.

Figure 4. Closeup views of some of the samples at the end of isotropic compression. (a) Discs series. (b) RCRs series. Grey particles represent floating particles (i.e. with zero or one contact).

Figure 5. Frontal view. Illustration of the biaxial shear test. Sample RCR $s=0.50$. The gradient of colour indicates vertical displacements. (a) Beginning of shearing. (b) Halfway of shearing.

Figure 6. Evolution of shear stress ratio $\boldsymbol{q} / \boldsymbol{p}$ and packing fraction $\boldsymbol{v}$ as functions of the vertical strain $\varepsilon_{y}$, for (a) the series composed of mono-shaped particles (discs), and (b) the series composed of particles with size and shape correlated (RCRs). Colours represent different values of the sample size-span $s$, which vary between $\mathrm{s}=0.1$ (close to uniform) and $\mathrm{s}=0.9$ (very well graded or polydisperse).

Figure 7. Comparison of steady-state angle of internal friction $\varphi_{s s}$ and packing fraction $v_{s s}$ as functions of the PSD-size-span $s$ of the two different series: Series 1 composed of mono-shaped (discs) particles, and Series 2 composed of particles with size and shape correlated (RCRs). Values shown are averages of data for strains over 35\% ( steady state, see Figure 6). The error bars capture the scatter of the readings (see Figure 6) and indicate the standard deviation. 


\section{Accepted manuscript doi: 10.1680/jgele.18.00216}

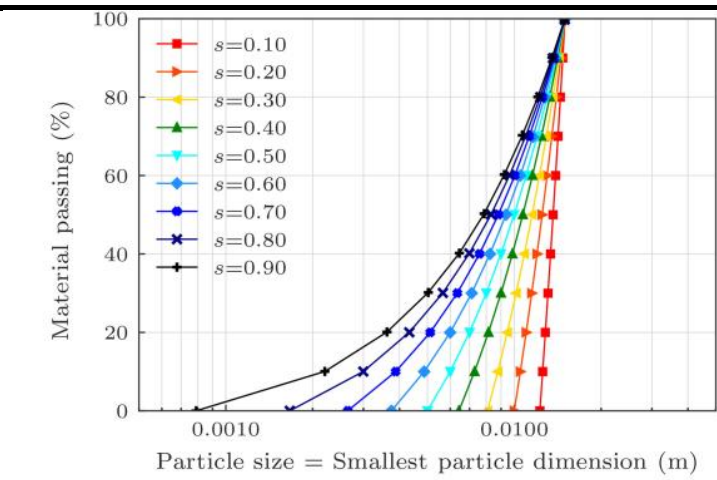

Fig. 1. 


\section{Accepted manuscript doi: 10.1680/jgele.18.00216}

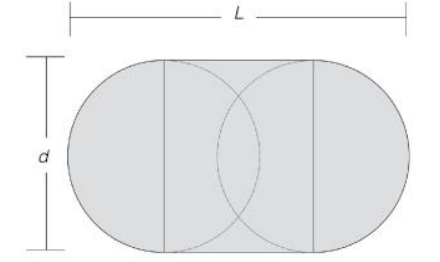

(a)

(b)

Fig. 2. 


\section{Accepted manuscript doi: 10.1680/jgele.18.00216}
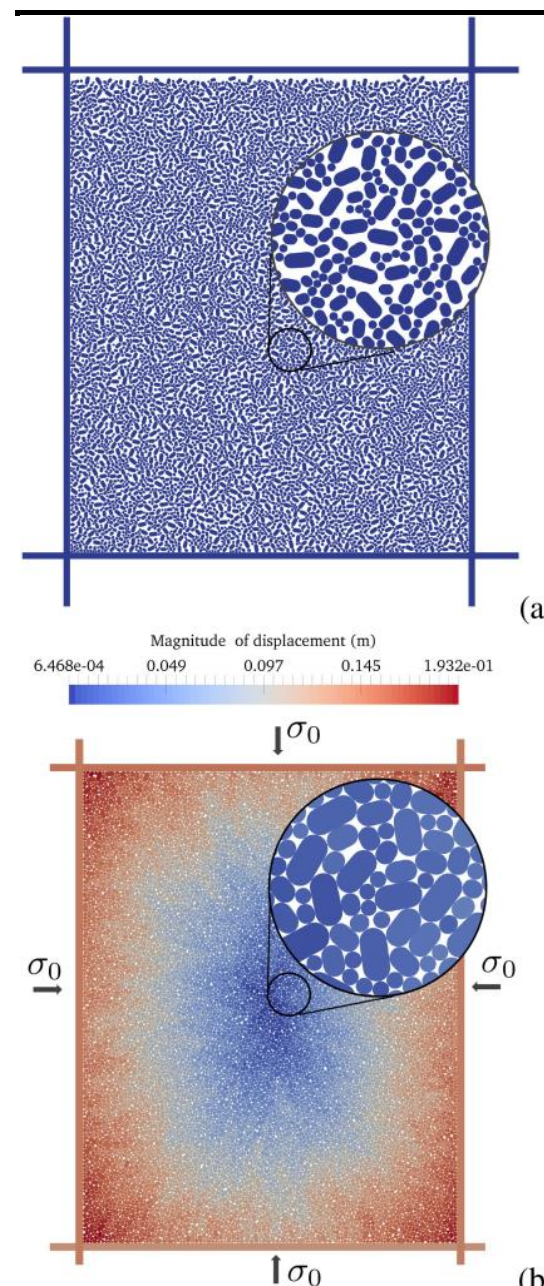

Fig. 3. 


\section{Accepted manuscript doi: 10.1680/jgele.18.00216}
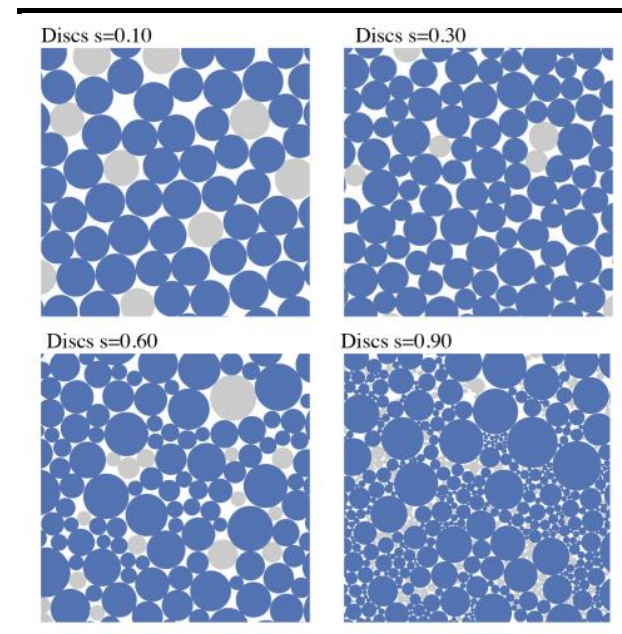

(a)
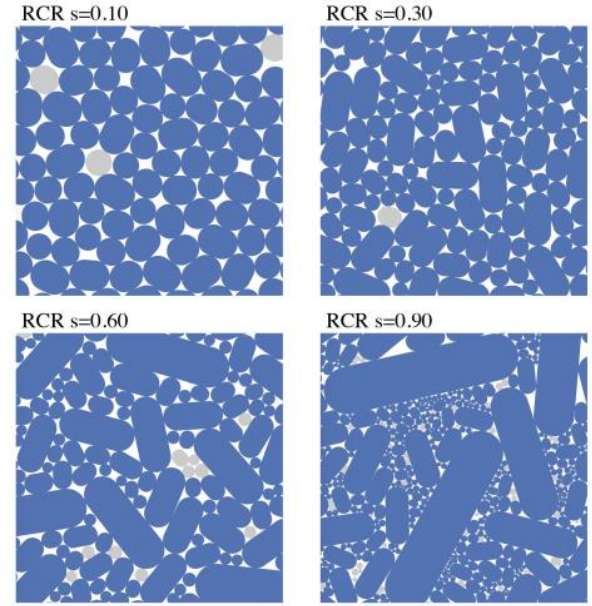

RCR $\mathrm{s}=0.90$

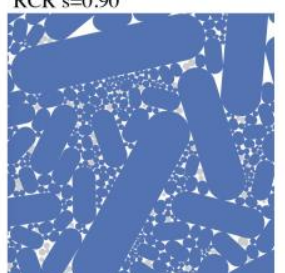

Fig. 4. 


\section{Accepted manuscript doi: 10.1680/jgele.18.00216}

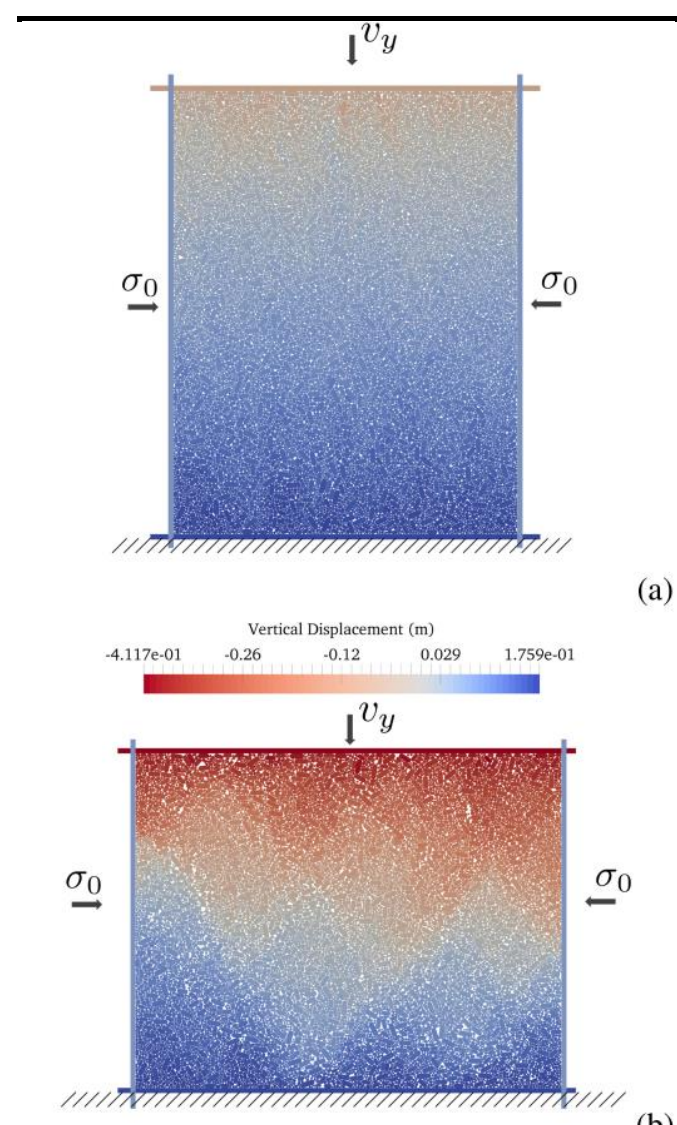

(b)

Fig. 5 . 


\section{Accepted manuscript doi: 10.1680/jgele.18.00216}

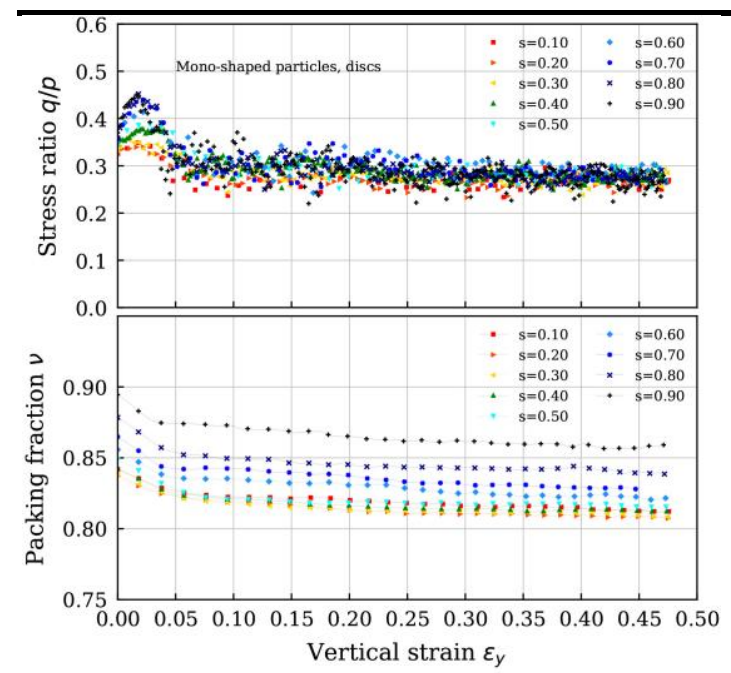

(a)

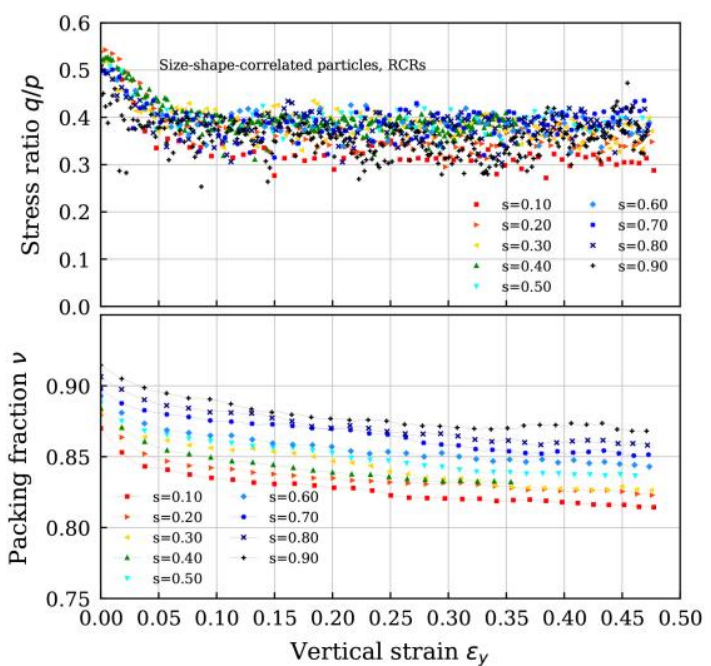

Fig. 6.

(b) 


\section{Accepted manuscript doi: 10.1680/jgele.18.00216}

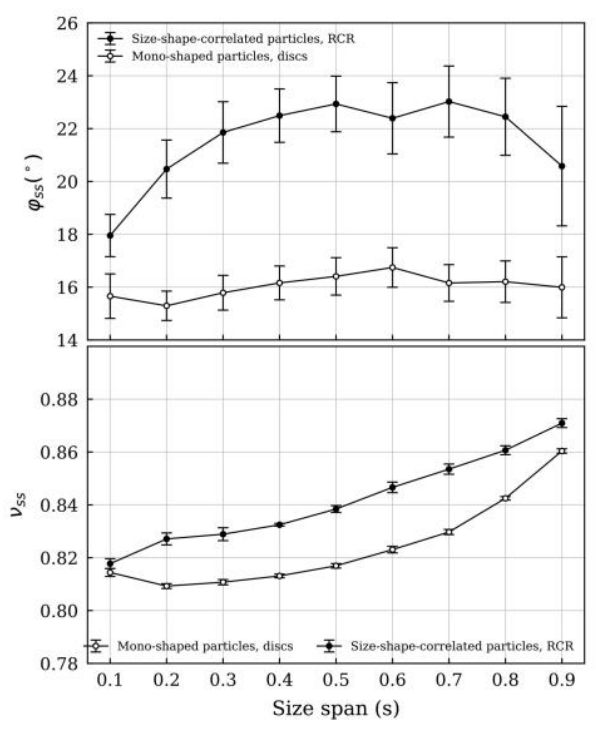

Fig. 7. 